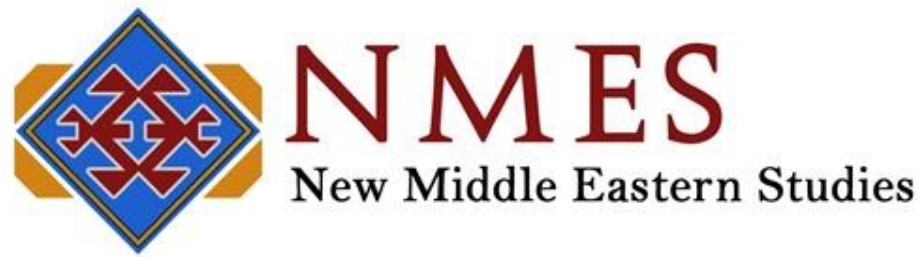

ISSN: 2051-0861

Publication details, including guidelines for submissions:

https://journals.le.ac.uk/ojs1/index.php/nmes

\title{
Exploration of Betrayal in Exploited Spaces: A Bakhtinian Study of The Shadow of the Crescent Moon
}

Author(s): Maryam Amjad Ali and Shamaila Dodhy

To cite this article: Ali, Maryam Amjad and Shamaila Dodhy (2021) "Exploration of Betrayal in Exploited Spaces: A Bakhtinian Study of The Shadow of the Crescent Moon", New Middle Eastern Studies 11 (1), pp. 1-15.

Online Publication Date: 23 July 2021

\section{Disclaimer and Copyright}

The NMES editors make every effort to ensure the accuracy of all the information contained in the journal. However, the Editors and the University of Leicester make no representations or warranties whatsoever as to the accuracy, completeness or suitability for any purpose of the content and disclaim all such representations and warranties whether express or implied to the maximum extent permitted by law. Any views expressed in this publication are the views of the authors and not the views of the Editors or the University of Leicester.

Copyright New Middle Eastern Studies, 2021. All rights reserved. No part of this publication may be reproduced, stored, transmitted or disseminated, in any form, or by any means, without prior written permission from New Middle Eastern Studies, to whom all requests to reproduce copyright material should be directed, in writing.

\section{Terms and Conditions}

This article may be used for research, teaching and private study purposes. Any substantial or systematic reproduction, re-distribution, re-selling, loan or sub-licensing, systematic supply or distribution in any form to anyone is expressly forbidden.

The publisher does not give any warranty express or implied or make any representation that the contents will be complete or accurate or up to date. The accuracy of any instructions, formulae and drug doses should be independently verified with primary sources. The publisher shall not be liable for any loss, actions, claims, proceedings, demand or costs or damages whatsoever or howsoever caused arising directly or indirectly in connection with or arising out of the use of this material. 


\title{
Exploration of Betrayal in Exploited Spaces: A Bakhtinian Study of The Shadow of the Crescent Moon
}

Maryam Amjad Ali ${ }^{*}$ and Shamaila Dodhy ${ }^{* *}$

\begin{abstract}
In post 9/11 literature, the wave of terrorism and its penetration into third world countries have been a serious concern. Since then, Pakistani literature has encapsulated the impact of war on terror in multi-faceted ways - investigating its implications on social, political and cultural levels. This article strives to focus on how betrayal seeps into the exploited spaces of the tribal areas. Bakhtinian studies assess the concept of betrayal from multiple perspectives, considering the applicability of the terms in unveiling the betrayal in relationships and state level as well. By the application of the concepts of chronotope and polyphony, the enforcement and discretion of being betrayed or by betraying have been analysed via considering the aftermaths of imposed war in terms of social-political aspects. The work has also focused on the penetration of betrayal in fictional tribal areas, by the youngsters of a native town who associated themselves with violent groups, spreading anarchy and disorder. The transgression from the order of the normal life due to encounter with grotesque reality has been unveiled in the study. With fear of violence, hope also germinates in the disordered world. It elucidates the multidimensional view of betrayal due to the disparities faced by the people of the tribal area.
\end{abstract}

Keywords: Betrayal; Exploitation; Chronotope; Spaces; Polyphony

\section{Introduction}

Literature is an embodiment of artistic expression of social, political, cultural and historical aspects of a certain time period. It has always proved useful to get an insight of a specific era by surfacing the social conditions as well as pulling the strands of history in congruent to the social conditions. Every era of human literary history is marked by some grand narrative encapsulating the politics as the core of the hysteria prevalent in one specific timeline. Similarly, the incident of 9/11 has vehement repercussions in the English literature written after the major event of the $21^{\text {st }}$ century, which has consequently changed the fate of many nations.

Post 9/11 literature demarcates the proliferation of terrorism in correlation to the imposed war on third world countries. Pakistani literature produced in the second decade of

\footnotetext{
*Maryam Amjad Ali, MPhil. Research Scholar, Institute of English Studies, University of the Punjab, Pakistan. Email: maryamali1010@yahoo.com.

${ }^{* * *}$ Shamaila Dodhy, Director, Institute of English Studies, University of the Punjab, Pakistan. Email: shamaila.english@pu.edu.pk.
} 
21st century circumvents the impact of terrorism on Pakistan and the aftermaths of imposed war with the tag of war on terror. The transition in the thematic concerns of the Pakistani literature from the post partition to post $9 / 11$ is prominent through the writings of young Pakistani writers.

Muneeza Shamsie in her book Hybrid Tapestries: The Development of Pakistani Literature in English presents the historical trajectory of literature produced from 1947 till 2014 by orchestrating the prominent themes imbibing the socio-historical aspects of Pakistan. Post partition literature begins with Mumtaz Shahnawaz's creative ability of penning down the reality. Shamsie describes the shades of Shahnawaz's themes in writings of other prominent writers as; "in Pakistani-English-fiction, the sufferings and mass migrations at Partition which Mumtaz Shahnazwaz circumvents would emerge later in the work of M.A. Seljouk, Zaib-un-Nisa Hmaidullah, Linda and Khalid Shah, and Mehr Nigar Masroor" (2017: 98).

After 1998, art in multidimensional forms has been strengthened by being applauded from the international media and institutes, in Pakistan. Young writers acclaimed recognition and fame through the celebration of globalism around the world. Shamsie condenses the beauty of flourishing of the art as;

This period also witnessed an unprecedented flowering to international acclaim of new, multicultural, multidimensional art forms by Pakistanis, a fusion of old and the new across the borders and nations. Pakistani pop music, paintings, sculptures, and films drew audiences from New York and London to Dubai and Singapore. Pakistani English- Literature was the leading light in the new firmament (2017: 382).

Soon after the flourishing period of art in Pakistan, the bombing of the World Trade Centre in USA instigates the sudden change in the paradigms of the literature produced mainly revolving around the themes of terrorism and the production of militant groups. The widespread of violence, horror, breakdown of law and order and conspiracies are a few noteworthy themes of literature published in the $21^{\text {st }}$ century.

A young writer such as Fatima Bhutto captures the changing socio-political conditions of Pakistan in her novel The Shadow of the Crescent Moon written in 2013. Due to its appeal to numerous readers and artistic excellence, the novel has been nominated for Bailey's Women Prize for Fiction in 2014. The novel is well-crafted story of five young different individuals yet related to one another. The story moves back and forth to encapsulate the demise, fear, terror, betrayal and hope in exploited spaces. Shamsie engrosses as a reader and a critic as; "The Shadow of The Crescent Moon, captures the dangers and confusion of conflicts, geopolitics, and religious extremism in Mir Ali, a town in tribal Waziristan" (2017: 608).

\section{Research Methodology}

The present article explores the penetration of betrayal in the exploited spaces of the tribal area by applying the approach of Bakhtin. In the context of $9 / 11$, the novel is analyzed 
through the chronotope and polyphony, concealed in the narrative of the text. The incorporation of hope, fear and terror in the novel aids in terms of deciphering the concept of betrayal at both the personal level and the state level.

Bakhtinian approach is applied to discover the underlying meaning of the text. The concept of chronotope from the Dialogic Imagination (1981) is applied on this analysis of The Shadow of the Crescent Moon (2013) to explore the tensions interwoven in an intricate manner in the novel. The chronotope aids in the multi-faceted interpretation of the geographical spaces mentioned in the text. The interfusion of space and time aids in probing the conflicts of the novel within the context of social, political and cultural aspects. Minor chronotopes like the staircase are juxtaposed against the major chronotope of road or streets to illustrate the mystery, renewals and carnivals in the text. Various chronotopes like the chronotope of road, thresholds and encounter are pivotal in the amalgamation of social classes, religions and nationalities.

Polyphony is another approach provided by Bakhtin, which forays the presence of multiple voices in the novel - all contributing to present individualistic points of view within the narrative of the novel. Bakhtin's concept of polyphony is discussed in detailed Problems of Dostoevsky Poetics (1984).

\section{Literature Review}

Bakhtinian studies have been quite relevant to the current case as it allows the investigation of the text from different points of view. The terms Bakhtin has coined for analysing literature have been widely applied on novels, dramas and poems to examine the underlying meaning of the literature in accordance to the relationship, between the text and the context in which it is written.

\section{The Concept of Chronotope}

Researchers have extensively used the term of chronotope to look upon a text from multiple lenses. The concepts of time and space have relevance in various fields like mathematics, philosophy, physics and many others. Einstein is the pioneer in giving suggestions and theories about absolute space and time. According to Einstein, the absolute space and time are independent of the objective reality around the perceivable object. The implication is that space and time are devoid of any physical quality, as they are rather abstract in nature.

Kant has also shed light on the issue of space and time. He proposes that both space and time entities are foreground in our sensible intuition. Space and time are discussed in terms of metaphysical and transcendental exposition. Space is present in the outer sense while time is part of our inner sense. Both space and time are symbiotic in nature; i.e. they are mutually dependent upon each other for the complete understanding of spatial and temporal representations.

Recently, the use of chronotope in identifying the relationship between the space and time hold significance as it allows the interpretation of interactions of space, human and time. Erol, in her research entitled "The Chronotope of Istanbul in Orhan Pamuk Istanbul", explores how the chronotope of Istanbul is emblematic of loss and pain encapsulating the 
comprehension of the affected people. In his memoirs, Pamuk is one of the characters in the text by becoming child and later he understands the melancholy of people with the image of the city and its spaces developed in the $19^{\text {th }}$ and $20^{\text {th }}$ century. It helps in deciphering the connections between the memories of city and memories of Pamuk. Erol writes;

$[\mathrm{H}]$ ow the chronotope of Istanbul is constituted to embody feelings of loss and pain as well as the active embrace of these as a life philosophy, that is, examines how Pamuk is able to represent Istanbul as the unchanging locus of hiizun (The Chronotope of Istanbul in Orhan Pamuk's Istanbul 2011: 658).

Similarly in the "The Time when... the Place Where: Chronotope and Chronologies in Love Labour's Lost", T. Collington and P. Collington describe the significance of chronotope in literary work as; "chronotopes act as narrative signposts for readers and provide underlying structure to overall design of a work at the levels of plot and theme" (2014: 792). Considering the significance of the chronotope as equivalent to the signpost allows in comprehension of the thematic concerns. T. Collington and P. Collington divide the chronotope into three categories as; "chronotope of retreat" (2014: 795), "chronotope of embassy" (2014: 795) and "chronotope of comic idyllic" (2014: 795). In reference to the division of chronotope into three categories, the chronotope of embassy (T. Collington and P. Collington 2014) aids in understanding the political tension as, "temporally speaking, the chronotope of embassy entails a series of political meetings and ceremonial events, transpiring over a finite time and ending with the conclusion of negotiations and the departure of visiting delegations" (T. Collington and P. Collington 2014: 800).

\section{The Concept of Polyphony}

Polyphony is also one of the central concepts used by Bakhtin, although the term has also relevance in the field of music where it is simply defined as; "a style of musical composition employing two or more simultaneous but relatively independent melodic lines" (MerriamWebster). In literature, the use of polyphony is to identify the multiple voices present in the text. Petty writes in research paper "Problems of Steinbeck's Poetics: Polyphony, Harmony and Dissonance in the Pastures of Heaven" as, "seen from the definition, the meaning of polyphony already contains within it the idea of harmony, which further transforms into a view of the disrupted harmony that underlies all the stories of Pastures and is essential to understanding Steinbeck's message and meaning" (2014: 174). The research paper focuses not only on the characterization of the pastures in terms of the creation of characters of everyday life possessing both the ambitions and the imperfections. It rather considers the thematic underlying unity in the construction of the short stories. Interestingly, with the polyphony, the elements of dissonance also goes in parallel which unravels the juxtaposition of harmony with the dissonance in the Steinback's short stories as Petty mentions; "creates a unique equilibrium between unity and fragmentariness, between a highly moralistic message and a subtly ironic tone" (2014: 173). 


\section{Past Studies on The Shadow Of The Crescent Moon}

Fatima Bhutto's The Shadow of the Crescent Moon was published in 2013. The novel has a rich fertile soil which can bore multi-valence interpretations of the context in which it is written. Political, social, historical and cultural context altogether aids in explaining the narrative of the text. It is Bhutto's debut novel, yet the art of writing in the novel has been applauded by various national and international critics. Due to its rich meaning and artistic significance, global newspapers such as The New York Times and Dawn have reviewed it in detail.

The novel has contemporary appeal in showcasing the turmoil of the tribal area which has been fighting for its representation for decades. Interestingly, Bhutto interweaves the political turbulence with cultural implications in the novel - describing the minute details of hospitality and the architecture of certain places like hospital and places where funerals are usually held. The New York Times views it as the manifestation of Bhutto's quote on Twitter which reflects Vladimir Nabokov saying, "My loathings are simple: stupidity, oppression, crime, cruelty, soft music".

For The New York Times, the novel is emblematic of the above mentioned loathings of Nabokov, as it encapsulates stupidity, oppression, crime, cruelty and soft music. The use of the technique of flashbacks in portraying the context of the narrative surfaces through one of the brothers known as Eman. Bhutto displays the ins and outs of the remote tribal area in an intricate manner as The New York Times reviews it as:

[A]nyone curious about this remote frontier region can experience its touch and feel, even its taste, through Bhutto's portraits of its daily life - the battered yellow Mehran taxis; the Chitrali pakol hats; the medicines that are older than most of the doctors at the hospitals where one brother works; the feral cats searching the building's corridors for, discarded placentas, which they eat out of half-open medical waste bins.

In addition, The New York Times also espouses upon the salient feature of enchantment in the novel. This again is an inspiration from Nabokov's way of writing fiction, encapsulating enchantment to create a thrill for readers. It also engrosses readers to get completely absorbed in the world of fiction. Adams reviews in The New York Times enchantment as; "she frequently withholds information from the reader to heighten the mystery, a technique that works best when applied sparingly".

Similarly, Razeshta Sethna reviews it in Dawn and pens the distinctive features of The Shadow of the Crescent Moon by exposing thematic concerns such as fundamentalism and political apathy as the recurrent themes in the novel. Sethna contextualizes the novel by inscribing in detail the political turmoil of unrest in tribal areas. She evidently explores the narrative of the novel by analysing it from the perspective of individual characters in the novel and also by the gender distinctions in the fictional and the real world. Regarding this issue, Sethna notes that "women are the heartbeat of this novel; they are extraordinary for their spirit and strength of heart and mind in a region where their voices are impermissible".

The review of the novel in Dawn is more of the reflection of the cause and effect relationship. It highlights the problems and consequences of problems surfacing in the novel. 
A particularly interesting interpretation is the longing for the unforgettable past and facing the brutal future in the exploited spaces. The thematic concerns as Sethna writes are; "Betrayal, allegiances, family ties and resilience come head to head with love, liberalism, and progression and changing ideology".

Considering the structure of the novel and the progression of the story in the novel, all are assimilated in the well-crafted manner irrespective of the fact that this is just Bhutto's debut novel. Her cryptic dialogues and picturesque description of the scenes gives it a miniature effect in portraying the FATA. On structure and art of the craftiness of novel, Sethna writes that "her fictional debut, even with its structural shortcomings, is an ambitious project with strong willed women (and men), memorable scenes written with emotional depth, and the clever use of suspense as a tool".

Amina Siddique in her work entitled "Dismantling the Stereotypes: Experiences of Autonomy and Identity in The Shadow of the Crescent Moon by Fatima Bhutto" explores the socio-political and historical circumstances by employing the theory of New Historicism by Green Blatt. Firstly, it unfolds the point of view that history is not authentic; rather the historians are also influenced by the numerous factors in the surrounding environment. Therefore, history is also prone to the subjectivity of the historian. Siddique mentions in the theoretical framework of her research about the subjectivity of the historians as; "historians live in particular time and place, and their views of both current and past events are influenced in innumerable conscious and unconscious ways by their own experience within their own culture" (2019: 7).

Secondly, Siddique employs ideas of Foucault in her analysis of different power structures operating in the society. The breaking of stereotypes in the exploited regions is also fundamental in understanding the relationship of power functional in different strata of the society. Even though the setting of the novel is a remote area, women are presented as dominant in multiple roles. Siddique notes that "women, who are dwelling in a region where they are under obligation to confirm to the patriarchal norms, have to face the aftermath of colonization as well. They are left with no option except for breaking through the patriarchal and colonial shackles at the cost of losing loved ones and forsaking relationships" (2019: 11).

Furthermore, Siddique forays the functioning of power as form of resistance by either escaping the situation or deliberately ignoring the circumstances. The roots of the new historicism are found in Foucault's ideology of power and its role in the society. In "Dismantling the Stereotypes: Experiences of Autonomy and Identity in The Shadow of the Crescent Moon by Fatima Bhutto", resistance is prominent through several characters. Aman Erum is the first one who resists the power by escaping the situation by going abroad. Siddique describes the definition of power in relationship to colonialism as follows:

[A]ll instances related to Aman Erum we can see the "power" exerted by the colonial hegemony this is directed from the powerful to the powerless, but Aman Erum after witnessing the chaotic situations of Mir Ali wants to flee abroad. This is his way of showing resistance by becoming the part of the colonizers who are responsible for the present situation of the tribal areas (2019: 14). 
In contrast to the typical representation of females in the Pakistani society, Bhutto attempts to portray female characters as autonomous and independent by claiming their spaces in the exploited regions of the tribal areas. The two female characters, Mina and Samarra, both act wisely in their own ways. Mina, as presented insane after the death of her son, dismantles the stereotypes by saving the life of her husband Sikander. Samarra, on the other hand, is also presented as a strong figure by confronting the forced disappearance of her father. Also, she is emblematic of the more liberal figure in the novel. Siddique describes her as follows: "Mina who appears to be insane and attends every unknown funeral gains more sympathies than from the reader but under the cover of this insanity she perhaps acts more sanely than any other white woman with brains" (2019: 21). Similarly she describes Samarra as; "Bhutto represents Samara stronger than ever. She does not make betrayal of Aman Erum as a reason of dejection rather a motivation to maintain her individuality" (2019: 23).

One of the most important issues Pakistanis have faced after $9 / 11$ is being labelled as the "facilitators of terrorism". Bhutto has given a picturesque effect of the aftermath of $9 / 11$ attack by labelling natives of tribal areas as terrorists. Since 9/11, Pakistan has faced the worst consequences as numerous Pakistanis have been murdered and martyred in the name of war on terror. The reflection of deaths is evident in various novel of Pakistan - describing the death toll and the bleak picture of the families of the deceased. The chaotic situation caused hazardous effects on socio-economic conditions of the country. Siddique mentions terrorism in her work by suggesting a way out of chaos: "Bhutto at first portrays the bleak picture of post 9/11 attacks by writing about militants, army officials, weapons, hand grenades, battalions and bloodshed but as the novel unfolds she projects her characters as finding a way out of this chaos and disturbance and the desire for peace" (2019: 22).

The review of the literature thus aids in the broadening of horizons to probe the text from multiple ways. Moreover, the application of Bakhtinian approach on several other texts harbour the understanding of the approach in integrating the terms in analysis of the selected text, enabling us to conceive the issues in the exploited areas confronting the worst circumstances. Past studies done on the selected text have explored the multi-layered meanings of the text. The present study is an attempt to fill the research gap of the selected text by employing Bakhtinian approach.

\section{Discussion: Resistance and Escapism in Exploited Spaces}

Fatima Bhutto's The Shadow of the Crescent Moon presents betrayal, political apathy, longing for a better future and continuous fear of violence in a small-town - Mir Ali. The socio-political aspects along with the historical background are interwoven in the novel to portray overall emotional and psychological conditions of the people living in turbulent surroundings. Bhutto attempts to explore the brutal impact of war along with the internal and external conflicts of the exploited region in an independent state.

The chronotope (time and space) are of pivotal importance in describing the narrative of the novel aiding in unfolding the social and political structures operative in any region. According to Bakhtin, chronotope is defined as "spatial and temporal indicators are fused into one carefully through-out, concrete whole" (FTC: 84). Similarly, in The Shadow of the Crescent Moon, the geographical spaces hold significance in relation to the time-period 
described in the novel. Both the space and time goes side by side in defining certain aspects of betrayal and political apathy.

Consideration of the chronotope of white house outlines several meanings like comfort, love, unity and convergence. Three brothers along with their mother live in a white house which is located on Sher Hakimullah Road. For Aman Erum, his house and town is insatiated and does not allow him to live a peaceful life so he has to leave his family and comfort zone. Above all, he leaves his parents to whom he shares a strong bond, to move abroad for higher studies and to earn a decent amount of money for the family. Apart from his family, Aman Erum also left behind Samarra to whom he promised that he would come back and marry her. Aman says to her that "it will be for our future" (Bhutto 2013: 40). Samarra, on the other hand, does not appreciate the idea of leaving and rather she prefers to stay in Mir Ali, and to relish the beautiful memories of life in her native town as she says: "I do not want to leave Mir Ali. I do not want to walk on roads that have no memory of my life. I want you and me to walk our children to streets we know by heart, streets that have known us since we were children" (Bhutto 2013: 41).

Similarly, the mention of the childhood memories of spending springs in Chitral are emblematic of pleasant and delightful experience of a bond shared by friends. Aman Erum's father Inayat along with Ghazan Afridi and other friends used to go to Chitral in the spring for fishing. For Samarra and Aman, Chitral as a spatial indicator and springs as temporal indicator together fused to give a streak of friendship in childhood which later on spiral into a relationship of love. Chitral is presented as a space for setting a contrast in the life of Aman and Samarra who used to enjoy all the activities together as Bhutto describes their company as; "Aman and Samarra crawled along the mossy trails on their hands and knees, digging up earthworms for the fisherman's morning excursions" (2013: 9). On the contrary, the time spent without going to Chitral together stands for parting their ways. When Samarra turns seventeen, she does not go to Chitral; in fact that summer, Aman Erum and Inayat do not wait for Ghazan to accompany them. The very act of non-conforming the tradition of going together foreshadows the traversing to separate paths of Samara and Aman. For Aman, living in Chitral would be of benefit for their future by becoming a tourist guide but Samarra never has a desire to leave her own place so she easily sweeps his idea of leaving home by saying that "no you can't choose your home. You can't just make a new one" (Bhutto 2013: 13). Thus, a continuous resistance is apparent between the both in Mir Ali and Chitral in the chronotope of delightfulness and pleasantness; in the moments before the chaos and disturbance or before the moments of transition in their life.

One other chronotope is the chronotope of transition which refers to the change taken place in the life of Aman Erum as one of the central characters of the novel and seemingly in the life of Samarra as well. The desire of leaving Mir Ali and moving abroad for higher education sets a contrast in two spaces of a same place. The contrast is set between the chronotopic significance of Mir Ali and Diplomatic Enclave located in the central space of the country.

Aman Erum belongs to one of the exploited regions of the country and for him, to imagine cities like Islamabad holds image of either fantasy or enchantment to go and visit them. Above all, going for an interview in the embassy seems like a chance that has the uncertainty of social climbing and resisting the operative structures in the region. For going 
to diplomatic enclave, he dresses himself in the best tailored suit by Zulfiqar sons - one of the oldest and established tailors of Mir Ali. Upon reaching there, he comes across a dissimilitude of mental image and real image. He always imagines diplomatic enclave in terms of colonial tall buildings but the place where he gets drop has "small brick houses, open sewers, barefoot children with matted hair chasing cars, men sitting on rickety wooden crates selling onions" (Bhutto 2013: 32). After enquiring the bus conductor about the enclave, he comes to know about that they are at the back side of the enclave. The dropping of the passengers at the back side of the building a bit far away from the actual building referred to as "the enormous white structure" (Bhutto 2013: 33) creates a space of otherness as well. Another disparity which Aman Erum comes across is how the presence of human beings is reduced to a bare minimum as they are not allowed to cross the front of the enclave as it disturbs firangis and disturbs their dogs as well. Owing to the fact that they are "walking their dogs" (Bhutto 2013: 32) in the early mornings, passengers must be dropped at the back and far away from the actual building.

Even in the Diplomatic Enclave, Aman Erum has to cross the spaces of military check which are visible and are continuously observing the applicants either through the cameras or through the men patrolling along with their German shepherds. Whenever anyone is signalled to proceed for the process, they have to cross spaces as "snipers were stationed on the roof" (Bhutto 2013: 33), which create an immense psychological fear on the applicants as if they are in a panopticon space where they are monitored from all of the four sides - developing continuous anxiety and stress. Same is the effect of waiting for hours standing in queue so the fusion of spatial and temporal factors altogether creates an enormous level of fear in the applicants.

On the other hand, Aman Erum himself sets a contrast about how different spaces have different types of surveillance as he considers the situation in Mir Ali more diplomatic and says that "it wasn't like in Mir Ali; it was worse here" (Bhutto 2013: 36). In Mir Ali, spaces like bazaar and streets used to be crowded with the army and then they used to arrest the suspected militants, while in Islamabad, people usually do not affect the peace of their dogs and lives on the other sides of the city as Bhutto writes that "these people in Islamabad lived on the periphery of their land so as not to disturb their guests" (2013: 37).

Furthermore, the chronotope of air space reveals one of the primary concerns of the narrative of the novel. Bhutto has meticulously described the different concerns by describing different settings of the novel which sets a sharp contrast in portraying the disparities between the peaceful and exploited regions of Pakistan. Bhutto as a novelist reflects the real incidents of the society and colours those real-life incidents with the strokes of fiction. The consideration of air space as one of the chronotopic elements in the novel sheds light on the concept of betrayal by depicting how the air space is the property of the natives, but it is given to the control of the foreign state. Moreover, it also shows how the super-powers controlling the developing states by hook or by crook and on the name of betterment manipulates others by extracting their information or causing exploitation, as Bhutto describes; "Pakistan had opened its air space to the empire, closed Quetta airport so that foreign soldiers could use it as a make shift base, allowed them access to their intelligence files, and put their invasive agencies at America's beck and call” (2013: 39). 
In addition to the mentioning of air spaces, spaces such as hospitals and public spaces (bazaars) hold layers of meanings to interpret the political apathy and betrayal rooted in the hidden manner in the exploited region. Bhutto also pens down how people are betrayed and, as a consequence, they also betray authority. The Hasan Faraz Government Hospital depicts inadequate facilities to operate and treat people. Due to its geographical location in the exploited region, it instigates the condition that is injurious to patients. With all the facilities that are essential for the hospital, the Hasan Faraz Government Hospital has facilities which any dispensary can offer. The condition of the hospital is described as; "it isn't a small operation - the two-storey Hasan Faraz Government Hospital has an emergency wing, an intensive care unit, a children's surgery ward, an ophthalmology OPD, and a maternity wardbut it is still being run like a dispensary" (Bhutto 2013: 48).

Not only the condition of hospital is hazardous but magnanimous amount of medicines delivered to the area is also hazardous as most of them are expired before they reach the natives of the Mir Ali. One important aspect is how the distributors peel off the expiry date and are involved in the inhuman act of not providing it to the patients at time. Thus, hospitals become a space which fails to grant health and comfort, and they rather become the space for instilling various diseases and deaths to the patients via distributing expired medicines, and due to inappropriate conditions of treatments in the public hospital. It affects them and instils betrayal and outlines how political apathy is seeped into "the mindless and brainless people". Bhutto describes political apathy as; "polio vaccines reach the hospitals unrefrigerated, held up for inspection by some politician's nephew who has been made chief customs officer at the port. The Hasan Faraz Government Hospital has stockpiles of tetanus, measles, BCG and mumps vaccines rendered completely ineffective by bureaucratic delays" (2013: 48).

Bhutto explicitly mentions how power operates at multiple levels, either apparent or in hidden manner, and that it leads people to behave in a certain manner. In Mir Ali, there is a restriction that people should not gather in public spaces as it may commiserate any resistance or betrayal in people. Therefore, everything tends to be under controlled to avoid any potential conflict or unrest in an already socio-economically exploited region. It also points to restrict the assimilation of the like-minded people so that they cannot foment any separatist/divergent views or foment abhorrence against the state. This very act of repressing people in the name of preventing them from spreading any hate is justifiable on a state level because state takes certain parameters to control anarchy in the state. On the other hand, it becomes difficult for the natives to understand preventive measures and instigates abhorrence and resistance. Their resistance is described as; "funerals and burials and prayer evenings became the meeting ground for the resistance. Even the dead were enlisted in the battle against the state" (Bhutto 2013: 50).

Thus, the aforementioned chronotopes portrays the cause and effects of the problem faced by the natives of the Mir Ali within a fictional state. The betrayal of people by the state and political apathy of the administration toward the natives become a cataclysmic process in spreading anarchy which ultimately affects the live of the common man who desires to live peacefully in their hometown. Therefore, the space and time together interludes to drape down the hidden meaning of the narrative of the novel. 


\section{Madness, Fear and Hope}

The Shadow of the Crescent Moon is an assimilation of chaos and harmony, hope and fear, freedom and imprisonment. Every voice in the novel claims its space by positing a unique and distinctive entity in the novel. It is of immense importance to demarcate how hope and freedom espouses symphony in environing of chaos and imprisonment.

Mina is one of the central female characters of the novel, who unshackles the stereotypical role of the females in exploited spaces not by betraying, but rather by resisting via empathizing in a political apathized space. She is a teacher of psychology by profession and she lives in a surrounding where continuous fear of violence penetrates every moment of the day. The fear of brutal violence and death causes an extreme turbulence by disturbing her emotionally, mentally and psychologically.

In coping with the everyday fear, Mina starts resisting it by attending funerals of unknown people around her and by washing dead bodies of children. The novel has a structure which sets forth and back certain events to understand the coherence about actions which have streaks in past. Mina is portrayed as a person who used to feel and integrate pain as part of her breathes as she usually visits the family of the dead. For her, paying visit is the only way to commiserate any bit of closeness and condolences to people around her. On the death of Karam, she visits his family and in the intense moment of grievance in the house, she repetitively says, "I am Mrs. Mina" (Bhutto 2013: 53). Her continuous repetition of the same thing shows her emotional perturbance. Moreover, it feels as if she is paying service to humanity simply by empathizing with unknown people. The emotion of empathy shows how fundamentally human beings around the globe have an unrecognized correspondence to pain and happiness as brain responds through mirror neurons.

Unfortunately, people around her begin to think that she is psychologically disturbed and that it is troublesome for family members to have her during funeral rituals. After sending her back home, they make a call to Sikander and request him "that he come and fetch his wife, who had caused a great amount of trouble on the day that Kamran's soul would be carried securely to heaven by the prayers of his loved ones" (Bhutto 2013: 53).

With every passing day, the numbers of deaths increase sporadically and it just becomes difficult for people around her to restrict Mina to her house. Sikander, her husband and a doctor, tries to support her emotionally by keeping her ignorant of the deaths in Mir Ali as it becomes involuntary for Mina to cry and she could not help herself. Whenever Zainab, her mother-in-law, enquires about her condition, Sikander replies that "she just needs rest" (Bhutto 2013: 57).

On the day of Eid, as everyone is present in the kitchen and enjoys the beginning of the festive day with a mouth-watering savoury breakfast including "sweet parathas and omelettes with diced tomatoes, onions, and green chilies. The air smells of the pepper being shaken onto the chopped onions, pungent but sweet" (Bhutto 2013: 2-3). Meanwhile, Sikander notices the absence of Mina from the kitchen and he finds her at the house of Habib - a young boy who died in an attack on Eid day when attackers mistakenly bombed the school van. The causality of school children affects Mina so she visits the house of Habib. For the family of Habib, Mina stands out as a person who can wash the body of dead boy in contrast 
to the families who declares her psychologically disturbed. Hence, Mina's presence is interpreted in an entirely different manner in this house.

In addition, the hysteria of Mina becomes the source of relief for the family of Habib as an elder man tells Sikander of her benign nature as such: "Mrs. Mina heard about Habib and came to us, she came to help us" (Bhutto 2013: 78). Not only Mina washes the dead body but also, she pays last rituals as; "her breathe blowing across the boy's face from his left ear to his right ear, so both the devils and the angels who follow him will hear the prayer and not stand in the way of his ascension" (Bhutto 2013: 78).

Amidst the polyphony of violence, chaos, and disorder; hope swirls out as the only medium to live upon by giving solace and calmness. Hope generates from the order of the routine life propelling how life continues despite all the violence and chaos. From the beginning of the novel, the element of hope and freedom creeps from the minute happenings as on Eid day, the breakfast becomes the source of subliming the violence. Similarly, Mina also imbibes hope by the poetry of Rehman Baba at the death of Habib, as she says; "I thought I could wake up this sleeping country with my cries, but still they sleep as if in a dream" (Bhutto 2013: 77).

Sikander is the reflection of an observer who is affected by the violence but he keeps an optimistic view of life by reviving the life of Mina through her past routine by trivializing things around her. For the purpose of distracting her from the casualties, he simply diverts her to music as Bhutto describes; "you always listened to it in the car; you know all the words of all songs. You used to beat your chest to the music, like it was devotional" (2013: 55).

Another significant symbol in the novel is tamarind seeds. Bhutto has set a contrast between how the seeds are used in two different occasions, emphasizing the different propensity of the seeds. In the beginning, the seeds are used for reciting Quranic verses at the death processions symbolic of death in any home as Bhutto writes; "Mina sat amongst the cross-legged women on the floor, who were tossing burnished beads into the centre of a white bed sheet, counting off prayers for then dead with each offering. Sometimes they were date pits or uncooked red beans, but most often they were dark-brown tamarind seeds" (2013: 51). In contrast to the mention of tamarind seeds on funerals, the tamarind seeds are also described as a symbol of hope and rejuvenation at the end of the novel. Despite the ambiguity of the death of Zalan - the son of Sikander and Mina - after the bomb attack, they simply move to the forest and the only spark of continuity of life is due to the dripping of water from the tamarind seeds. Bhutto, with true artistic competence, describes hope as; "and as he drives along the winding roads of Mir Ali's forest paths, the light rain falling on his windscreen, he hears the tap tap tap of the tamarind seeds" (2013: 231).

\section{Conclusion}

The analysis of The Shadow of the Crescent Moon according to the Bakhtinian studies in this article provides certain new observations about the novel. In the present article, the narrative of the novel is explored through the lenses of chronotope and polyphony. The investigation of betrayal in the exploited spaces of the fictional town of Mir Ali is penned down in coherence with the integration of the socio-political aspect of the novel. 
In considering the exploration of chronotope in the novel, it leashes out how peaceful spaces are transformed into war spaces. Bhutto meticulously describes the emotional and psychological conditions of the people living in a war space, by using the technique of flashback to structure the novel. A sharp contrast between the emotional states of people is unravelled through the time spent in Chitral in contrast to the desire of leaving the state. Aman Erum is a reflection of the attitude of young people towards the political circumstances of the society. The austerity with which the youngsters simply resist the violence is to escape from the real-life situations as Aman Erum left the hometown to spend his life in peace and hence encapsulates the desire to have a prosperous future. On the other hand, Samarra is emblematic of the youngsters who are motivated by the feelings of the revenge which insinuates betrayal in them.

A space like the diplomatic enclave posits another important concern of the postcolonial world that is strict surveillance. In lieu of surveillance, the social aspect of the society is revealed as the individuals are monitored which continuously harbour anxiety and stress. Interestingly, the description of the air space being in the control of the foreign state unravels the foreign involvement in so-called third world countries to insinuate global violence and betrayal. Moreover, the insensitivity of the elected representative of the tribal areas is exposed through the conditions of the hospitals which become the chief cause of casualties in Mir Ali due to magnanimous ignorance on the behalf of the political representative of the tribal area.

The polyphony in the novel simulates how hope has pre-dominance over violence and war. In the investigation of betrayal in exploited spaces, traces of hope are also embedded in the novel. With the continuous fear of violence Mina loses her psychological stability and involves herself in attending the funerals of unknown people in Mir Ali. Mina is indifferent to all the characters of the novel, the continuous description of Mina as somebody whose involuntary presence in the funerals posits madness. Most people around her consider Mina as mad, but her fanatic devotion actually portrays the core of humanity. The ability to feel pain for others is expressed through her as she involuntarily sobs on hearing the death of unknown people. In her supposed madness, she just proves to be supernatural being in washing the dead body of a young boy. It is her madness which propels her to ponder upon the few remnants of hope. Hope in the novel is derived through the poetry of Rehman Baba and music which creates harmony, thus foreshadowing the liability of harmony in exploited spaces with the freedom as a by-product.

Another significant symbol of hope in the novel is of tamarind seeds which has two different connotations in the novel. First it is used at the death rituals for the recitation of the holy verses, but in the end of the novel the dripping of water from the tamarind seeds sets a binary of life and death. Thus, the dripping of the water symbolizes the continuity of life in the aftermath of the devastation caused by the bomb attack. Moreover, a contrast is developed as Mina is unable to control her at the death of the unknown people, however at the end she derives hope from the dripping of water from the tamarind seed as the death of her son is subject to ambiguity in the novel.

In conclusion, Bakhtinian studies have proved significant in yielding the interpretation of betrayal in the exploited spaces in The Shadow of the Crescent Moon. The chronotope of geographical spaces encapsulates betrayal by comparing the peaceful spaces with the war 
zone spaces. At last, amidst numerous disparities and violence, the rebirth of hope stems from water - which encapsulates the continuity of life.

\section{References}

Adams, L. (2015) 'The Shadow of the Crescent Moon', The New York Times, 15 April.

Bakhtin, M. M. and Holquist, M. (1981) The Dialogic Imagination: Four Essays (Austin: University of Texas Press).

Bhutto, F. (2013) The Shadow of the Crescent Moon (London and New York: Penguin).

Collington, T. and Collington, P. (2014) 'The Time When... The Place Where": Chronotopes and Chronologies in "Love's Labour's Lost', Studies in Philology 111 (4), pp. 786-820.

Erol, S. (2011) 'The Chronotope of Istanbul in Orhan Pamuk's Memoir "Istanbul"', International Journal of Middle East Studies 43 (4), pp. 655-676.

Heimer, J. (1967) 'Betrayal, Confession, Attempted Redemption, and Punishment in Nostromo’, Texas Studies in Literature and Language 8 (4), pp. 561-579.

Petty, A. (2014) 'Problems of Steinbeck's Poetics: Polyphony, Harmony, and Dissonance in The Pastures of Heaven', The Steinbeck Review 11 (2), pp. 171-184.

Shamsie, M. (2017) Hybrid Tapestries: The Development of Pakistani Literature in English (Oxford and New York: Oxford University Press).

Siddique, A. (2019) Dismantling the Stereotypes: Experiences of Autonomy and Identity in The Shadow of the Crescent Moon (Islamabad: COMSATS University Islamabad).

Sethna, R. (2014) 'Review of The Shadow of the Crescent Moon', Dawn, 12 January.

\section{About the Authors}

Maryam Amjad Ali is MPhil scholar at the Institute of English Studies, University of the Punjab, Pakistan.

Shamaila Dodhy is Director of the Institute of English Studies, University of the Punjab, Pakistan. Shamaila Dodhy holds a PhD in English Literature from Universiti Putra Malaysia, Malaysia. Her interdisciplinary research focuses on Trauma Studies, Literature of Trauma, Attachment Trauma Theory, African-American Literature and African Literature. Dodhy's teaching and research specializations are in narratives of exile and migration from South Asia. Currently she is doing research on inter-sectionality and colorism, a question further problematized by the political discourse of identity. She has published in a range of national 
New Middle Eastern Studies, 11 (1)

and international journals. Besides teaching and research, she also holds several administrative posts. 